[4] Lai CC, et al., Increased serum fibroblast growth factor-23 and decreased bone turnover in patients with systemic lupus erythematosus under treatment with cyclosporine and steroid but not steroid only. Osteoporos Int. 2015 Feb; 26(2):601-10.

[5] Durlacher-Betzer K, et al., Interleukin-6 contributes to the increase in fibroblast growth factor 23 expression in acute and chronic kidney disease. Kidney Int., 2018 Aug; 94(2):315-325.

[6] Faul C, et al. FGF23 induces left ventricular hypertrophy. J Clin Invest., 2011 121:4393-4408.

Disclosure of Interests: None declared

DOI: 10.1136/annrheumdis-2019-eular.2856

\section{AB0491 THE PERFORMANCE OF A RENAL ACTIVITY INDEX IN LUPUS NEPHRITIS IN INDUCTION THERAPY}

Najla Aljaberi, Theresa Hennard, Arjun Mathur, Hermine Brunner. Cincinnati Children's Hospital Medical Center, Pediatric Rheumatology, Cincinnati, United States of America

Background: Renal involvement in systemic lupus erythematosus (SLE) is associated with high morbidity and mortality ${ }^{1}$. Current standard tools to monitor lupus nephritis (LN) are suboptimal compared to the invasive renal biopsy ${ }^{2}$. The renal activity index in lupus (RAIL) was developed using 6 urinary biomarkers to reflect disease activity. In children this tool was $92 \%$ accurate in identifying active $\mathrm{LN}^{3}$.

Objectives: We aim to study the changes in this score in relation to induction treatment in $\mathrm{LN}$.

Methods: Urine samples were collected from active LN patients prior to induction treatment for $\mathrm{LN}$ and serially afterwards, coinciding with clinical visits. Luminex Bead Multiplex Assay was used for the analyses of urine biomarkers included in the RAIL score (neutrophil gelatinase-associated lipocalin, ceruloplasmin, monocyte chemoattractant protein-1, adiponectin, hemopexin, kidney injury molecule-1). RAIL scores were calculated per the defined algorithm for each urine sample. Data collected include LN histologic classification (International Society of Nephrology (ISN)/Renal Pathology Society (RPS) classification system), renal SLE disease activity index (rSLEDAI) score and type of therapy.

Results: At the time of the analysis, data from 6 active LN patients were collected longitudinally. Patients were all females and all had class IV LN per the ISN/RPS. Renal SLEDAI scores were on the higher end $(M=11.3$, $S D=3.9)$. All patients were started on intravenous (IV) methylprednisolone and cyclophosphamide (CYC) therapy. All but one patient completed 6 doses of monthly CYC before switching to oral mycophenolate mofetil therapy. The RAIL scores for the 6 patients ranged between -1.8 and 3.29. All patients had reductions in their RAIL score at 2-3 months period at an average of $322 \%$ decline from baseline (Figure 1). At the end of induction treatment or at the 5-6 months interval, 5/6 samples were available for analysis and showed that $4 / 5$ patients maintained a decline of RAIL scores below the baseline. Of note the patient with higher RAIL score at the end of treatment had only 3 monthly doses of CYC. All rSLEDAI scores decreased between baseline and the 6 months interval. However, one patient with known medication nonadherence had a flare of LN at the 6 months point leading to increased rSLEDAI.

Conclusion: RAIL scores show overall improvement from baseline with LN induction therapy. Lack of improvement was associated with flare of disease. Additional data points and a larger study sample are required to study the ability of the RAIL score to reflect clinical improvement of LN.

\section{REFERENCES}

[1] Almaani S, Meara A, Rovin BH. Update on Lupus Nephritis. Clinical Journal of

[2] the American Society of Nephrology : CJASN 2017: 12(5), 825-835.

[3] Sule SD, Moodalbail DG, Burnham J, Fivush B, Furth SL. Predictors of kidney disease in a cohort of pediatric patients with lupus. Lupus 2015; 24 : 862-68.

[4] Brunner HI, Bennett MR, Abulaban K, et al. Development of a novel renal activity index of lupus nephritis in children and young adults. Arthritis Care Res (Hoboken) 2016; 68(7): 1003-11.

Disclosure of Interests: NAJLA ALJABERI: None declared, Theresa Hennard: None declared, Arjun Mathur: None declared, Hermine Brunner Grant/research support from: Bristol-Myers Squibb, Pfizer, Consultant for:
Pfizer, Bristol-Myers Squibb, Janssen, Novartis, Lilly, Roche, GlaxoSmithKline, Sanofi, Speakers bureau: Novartis, Roche

Appendix:

Changes in the RAIL Score with LN Induction Therapy

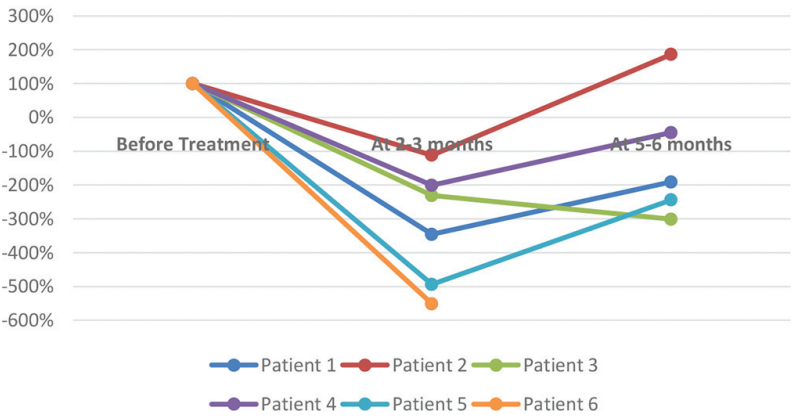

Figure 1. Changes in the RAIL score from baseline, at 2-3 months and at 5-6 months in 6 patients with LN. Baseline value is assigned $100 \%$.

DOI: 10.1136/annrheumdis-2019-eular.2005

\begin{tabular}{l|l}
\hline AB0492 & PREVALENCE OF IGA ANTICARDIOLIPIN ANTIBODY \\
AND ITS ASSOCIATION WITH PREGNANCY MORBIDITY \\
IN ASIAN INDIAN PATIENTS WITH PRIMARY \\
ANTIPHOSPHOLIPID ANTIBODY SYNDROME AND \\
SYSTEMIC LUPUS ERYTHEMATOSUS - A CROSS \\
SECTIONAL STUDY
\end{tabular}

Harshini Alur Shivakumar ${ }^{1}$, K Jayakanthan ${ }^{1}$, Mahasampath Gowri ${ }^{2}$, John Mathew ${ }^{1}$, Debashish Danda ${ }^{1}{ }^{1}$ Christian Medical College, Clinical Immunology and Rheumatology, Vellore, India; ${ }^{2}$ Christian Medical College, Biostatistics, Vellore, India

Background: There are many clinical and laboratory parameters which have been proven to be associated with increased risk of pregnancy morbidity in patients with SLE and APS. This study was undertaken as there is a lacuna in explaining all the pregnancy related morbidity in this group Objectives: Primary: Correlation of $\lg A$ anticardiolipin antibody with the risk for pregnancy morbidity in patients with APS/SLE

Secondary: Association of $\lg A$ Anticardiolipin antibody with the risk of thromboembolic events

Methods: Patients diagnosed as SLE and/or Primary APS who are married and conceived atleast once were recruited and $3 \mathrm{ml}$ blood sample was obtained from them. Patients with history of recurrent infections, which could suggest probable $\lg A$ deficiency, were excluded. Demographic data including duration of illness, number of pregnancies, thromboembolic events, disease activity were noted. They were categorized into two different groups depending on whether they had a pregnancy morbidity or not The blood samples were subjected to IgA Anticardiolipin assay by ELISA. Results: A total number of 186 patients were recruited with mean age $34.54(+/-7.32) y e a r s$, mean duration of illness of $5.52(+/-4.31) y r s$ with a diagnosis of $76.88 \%$ SLE, $7.53 \%$ primary APS and $15.59 \%$ SLE with secondary APS. On assessment of disease activity, mean SLEDAI score was found to be $4.46+/-6.32$. Out of the total, $14.71 \%$ patients had conceived once, $14.56 \%$ twice, $16.72 \%$ patients thrice and $18.41 \%$ had conceived more than three times. $36.56 \%$ patients had pregnancy morbidity (majority being pregnancy induced hypertension $14.52 \%$, prematurity $11.29 \%$, IUGR $10.22 \%$, pre-ecclampsia in $3.76 \%$, eclampsia $1.08 \%$,), $19.35 \%$ patients had history of thromboembolic events $(6.45 \%$ pulmonary embolism, $5.38 \%$ deep vein thrombosis, 3.76\% visceral vessel thrombosis, $0.54 \%$ cortical vein thrombosis, $6.99 \%$ other vessel thrombosis). $33.87 \%$ patients had positivity for antiphospholipid antibodies with $27.82 \%$ lupus anticoagulant positive, 20.97\% IgG Anticardiolipin positive and $17.35 \%$ anti-beta2 glycoprotein positive. IgA Anticardiolipin was found to be positive in $4.84 \%(n=9)$ out of which, $10.29 \%$ were in the group with pregnancy morbidity as against $1.69 \%$ without pregnancy morbidity. Out of the total positives titre in $37.5 \%$ were indeterminate, $25 \%$ low positive and $37.5 \%$ high positive. All patients who had high titre positivity had pregnancy morbidity. The positivity of $\lg A$ anticardiolipin in the patient group with thromboembolic events was $5.56 \%$.

\begin{tabular}{lcc}
\hline IgA Anticardiolipin & Pregnancy morbidity & No pregnancy morbidity \\
\hline Positive & $7(10.29 \%)$ & $2(1.69 \%)$ \\
Negative & $69(89.71 \%)$ & $116(98.31 \%)$ \\
\hline
\end{tabular}


Conclusion: Among patients with SLE, APS or SLE and APS, the overall prevalence of IgA anticardiolipin antibody was found to be about $4.84 \%$, which is much less as compared to the percentages reported by other groups $^{[1]} \operatorname{IgA}$ Anticardiolipin antibody positivity was more in patients with pregnancy morbidity compared to patients without a pregnancy morbidity. In this study however, statistical significance was not reached. Similar studies with larger number of patients are required. We also need to prospectively follow up such patients with IgA ACLA and evaluate for morbidity during pregnancy

\section{REFERENCES}

[1] Clinical significance of IgA anticardiolipin and anti-beta2-GP1 antibodies in patients with systemic lupus erythematosus and primary antiphospholipid syndrome, Clin Rheumatol. 2006 Mar;25(2):199-204

Disclosure of Interests: None declared

DOI: 10.1136/annrheumdis-2019-eular.7181

\section{AB0493 IMMUNOGLOBULINS AFTER ACUTE PHYSICAL EXERCISE IN PATIENTS WITH SYSTEMIC LUPUS ERYTHEMATOSUS}

Rosane Gouveia Vilela Machado ${ }^{1}$, Jozelia Rêgo ${ }^{2}$, Ana Carolina de Oliveira e Silva Montandon², Heloísa Gouveia Machado², Cláudio André Barbosa Lira² ${ }^{2}$, Ludimila Paula Vaz Cardoso ${ }^{1}$, Michelle Rocha Parise ${ }^{1}$, Ricardo Borges Viana ${ }^{2}$, Vitalina Barbosa ${ }^{2}$, Nílzio Da Silva ${ }^{2} .{ }^{1}$ Universidade Federal de Goiás, Jataí, Brazil; ${ }^{2}$ Universidade Federal de Goiás, Goiânia, Brazil

Background: Moderate exercise improves the functions of the immune system. The results of serum immunoglobulins in response to acute physical exercise are conflicting, but in general, there is an increase in serum immunoglobulins in athletes and non-athletes after maximal and submaximal exercise. The effects of acute physical exercise on serum immunoglobulin in patients with systemic lupus erythematosus are unknown.

Objectives: To determine the serum levels of $\lg G$, $\lg M$ and $\lg A$ immunoglobulins in patients with systemic lupus erythematosus after a single session of acute aerobic exercise.

Methods: Thirty-one women with SLE (ACR1997 and/or SLICC 2012 criteria),11 with active lupus and 20 with inactive lupus, and 24 healthy women, who were matched by gender, age, and body mass index, participated in this study. All subjects underwent a maximal exercise test on motorized treadmill, with increases in velocity every minute until exhaustion, to evaluate the speed $(\mathrm{km} / \mathrm{h})$, heart rate, Borg scale $(6-20)$, and the reason for stopping the test (fatigue and/or dyspnea). Samples of blood were collected in the morning, after an 8-hour fast and immediately after acute physical activity, and stored in a freezer at $-80^{\circ} \mathrm{C}$ until the tests were performed. Immunoglobulin IgG, IgM and $\lg A$ assay was performed by turbitometry according to the manufacturer (Turbiquest, Labtest Diagnostic S.A). Results: There was an increase in both $\lg G$ and $\lg A$ serum levels after physical activity in SLE patients ( $p=0.004$ for $\lg G$ and $p=0.002$ for $\lg A$ ) and healthy controls ( $p<0.001$ for $\lg G$ and $p<0.001$ for $\lg A$ ) (Figure1). Inactive SLE patients showed higher levels of $\lg G$ and $\lg A$ after exercise ( $p=0.006$ and $p=0.010$, respectively) (Figure 2$)$, in comparison with the active SLE patients. There was no difference in IgM serum levels before and after the exercise test in both groups.
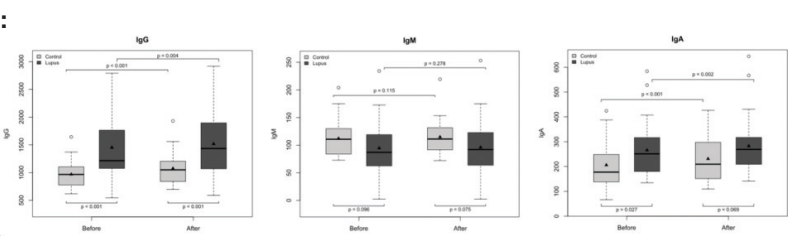

Figure 1. Comparison of $\lg G$, $\lg M$ and $\lg A$ immunoglobulins intra and inter-group lupus and control $\boldsymbol{\Delta}=$ Average
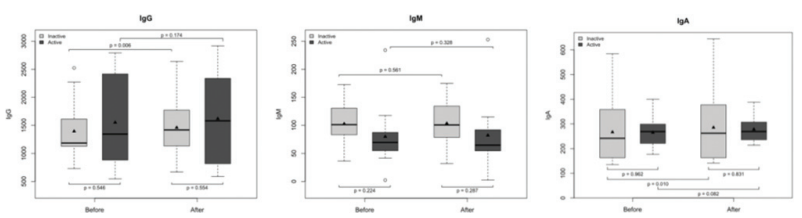

Figure 2. Comparison of $\lg G$, $\lg M$ and $\lg A$ immunoglobulins intra- and inter-group of active and inactive lupus. $\mathbf{\Delta}=$ Average
Conclusion: Patients with SLE, mainly with inactive disease, responded to acute physical exercise with increased $\lg G$ and $\lg A$ serum levels, similarly to healthy controls.

\section{REFERENCES}

[1] Nehlsen-Cannarella SL, et al. The effects of acute moderate exercise on lymphocyte function and serum immunoglobulin levels. Int J Sports Med. 1991; 12(4): 391-398.

[2] Nieman DC and Nehlsen-Cannarella SL.The effects of acute and chronic exercise of immunoglobulins. Sports Med. 1991; 11(3): 183-201.

[3] Ochoa-Martínez PY, et al. Cinética de la inmunoglobulina-A salival (IgAs) en adultos jóvenes con capacidad aeróbica promedio o excelente antes y después de una prueba de esfuerzo máximo. Revista Chilena de Infectología, 2017; 34: 27-32.

Disclosure of Interests: None declared

DOI: 10.1136/annrheumdis-2019-eular.2282

\section{AB0494 ACTIVITY OF PURINE AND PYRIMIDINE METABOLISM ENZYMES IN SYSTEMIC LUPUS ERYTHEMATOSUS: ENZYMATIC PATTERNS OF BLOOD PLASMA AND LYSED LYMPHOCYTES}

Svetlana Bedina $^{1}$, Andrei Trofimenko $^{1,2}$, Elena Mozgovaya ${ }^{1}$, Svetlana Spitsina $^{1,2}$ Ekaterina Tikhomirova ${ }^{1}$, Maria Mamus ${ }^{1}$, Irina Zborovskaya ${ }^{1,2}$. ${ }^{1}$ Research Institute of Clinical and Experimental Rheumatology named after A.B. Zborovsky, Volgograd, Russian Federation; ${ }^{2}$ Volgograd State Medical University, Volgograd, Russian Federation

Background: Cytotoxic immunosuppressants are widely used nowadays for outcome improvement and better quality of life in severe systemic lupus erythematosus (SLE). As purine and pyrimidine metabolism suggest to be the major targets of most cytotoxic immunosuppressants, enzyme profiling of these metabolic pathways is recognized as an important step for a better balance between efficiency and safety in clinical practice.

Objectives: To characterize enzymatic patterns of the major enzymes of purine and pyrimidine metabolic pathways in systemic lupus erythematosus. Methods: The research was carried out in agreement with the WMA Declaration of Helsinki principles. 50 adult SLE patients from the rheumatology unit of Volgograd Clinical Emergency Hospital \#25 and 30 healthy controls were included in the study. Diagnosis of SLE had been established using ACR criteria (1997), and activity was assessed by means of ECLAM scale. Activities of 10 major enzymes involved in purine and pyrimidine metabolic pathways: adenosine deaminase (ADA; E.C. 3.5.4.4) adenosine kinase (AK; E.C. 2.7.1.20), guanylate kinase (GK; E.C. 2.7.4.8), dihydroorotate dehydrogenase (DODG; E.C. 1.3.5.2), IMP dehydrogenase (IMPDG; E.C. 1.1.1.205), purine nucleoside phosphorylase (PNP; E.C. 2.4.2.1), thymidine kinase (TK; E.C. 2.7.1.21), thymidine phosphorylase (TP; E.C. 2.4.2.4), uracil/thymidine dehydrogenase (UDG; E.C. 1.17.99.4), cytidine deaminase (CDA; E.C. 3.5.4.5) were measured in blood plasma and lysed lymphocytes. Results are expressed as mean \pm standard error. Statististical comparison tests are selected in line with common guidelines, differences were considered significant when $p<0.05$. Results: Enzymatic profiles in plasma of SLE patients are characterized by increased PNP, AK, UDG, IMPDG, CDA, TK, and DODG activities ADA and GK were found to decrease. Lyzed lymphocytes are revealed however to increased AK, IMPDG, TK, as well as decreased PNP, ADA GK, CDA, and TP activities. We have also found that most enzyme activities significantly correlate with ECLAM score in accordance with our previous results [1]. Plasma PNP, AK, UDG, IMPDG, CD, TK and DODG activities positively correlated with ECLAM score, as well as lymphocyte AK, IMPDG, and TK activities did. Negative correlations with ECLAM score were revealed for plasma $A D A$ and $T P$, and also for lymphocyte PNP, ADA, GK, UDG, CD, TP, and DODG. Plasma PNP, AK, IMPDG and lymphocyte PNP, ADA, AK activities had the closest relations with minimal SLE activity, being a candidate markers of it

Conclusion: The enzymatic patterns studied can be used as auxiliary markers of SLE activity, with special emphasis on minimal disease activity.

\section{REFERENCES}

[1] Zborovskaya IA, Martemyanov VF, Zborovsky AB, et al. Purine nucleoside phosphorylase activity in rheumatic diseases. Ann Rheum Dis. 2009;68 (Suppl3):764

Disclosure of Interests: None declared DOI: 10.1136/annrheumdis-2019-eular.4622 